\title{
Formation mechanism of the Lidang circular structure in the Guangxi Province
}

\author{
Pan Yan' ${ }^{1}$, ZhiYong Xiao ${ }^{1,2,3}{ }^{*}$, YiZhen Ma', YiChen Wang ${ }^{1}$, and Jiang Pu' \\ 1Planetary Science Institute, School of Earth Sciences, China University of Geosciences (Wuhan), Wuhan 430074, China; \\ 2State Key Laboratory of Lunar and Planetary Sciences, Macau University of Science and Technology, Macau 999078, China; \\ ${ }^{3}$ Chinese Academy of Sciences, Center for Excellence in Comparative Planetology, Beijing 100864, China
}

\begin{abstract}
The Lidang circular structure in the center of the Guangxi Province is about $8 \mathrm{~km}$ in diameter. This structure appears as an abnormal shallow depression that has disturbed the rather harmonic regional joint systems. Its unique occurrence in the whole region, the circular morphology, negative topography, and the spatial distribution of interior and exterior strata are all consistent with those of impact craters that are formed by asteroidal or cometary collision. To test the impact hypothesis, we carried out both field investigation and remote sensing study of this structure. Regional geological history suggests that if the impact hypothesis were correct, the impact event should have occurred at or after the Early Permian. Field investigation found that the strata inside and outside the crater are dominated by parallel stacks of Lower and Upper Permian limestone that have various thicknesses and different mud contents. The layers of limestone within and outside the circular structure have identical attitudes; no structural disturbances were visible in the outcrops. Field investigations provide conclusive evidence against the impact cratering hypothesis. A high-resolution digital elevation model shows that the spatial distribution of rounded mountains within the structure is controlled by faint but continual extension of joints, suggesting that the crater interior has gone through a much higher degree of erosion. Therefore, regional joints that had once existed within the crater are preserved less well than exterior terrains, forming the abruptly disrupted circular depression. Differential erosion, as the possible formation mechanism of the Lidang structure, is consistent with the different mud contents found between the interior and exterior limestone. The circular outline of this structure may correspond to the shape of the original deposition basin. In conclusion, the Lidang circular structure is a polje formed by karstification, not an astrobleme.
\end{abstract}

Keywords: impact crater; impact cratering; geomorphology; karst; Guangxi

Citation: Yan, P., Xiao, Z. Y., Ma, Y. Z., Wang, Y. C., and Pu, J. (2019). Formation mechanism of the Lidang circular structure in the Guangxi Province. Earth Planet. Phys., 3(4), 298-304. http://doi.org/10.26464/epp2019031

\section{Introduction}

Various-sized impact craters, i.e., circular depressions formed by hypervelocity collisions between celestial bodies, are the most common features across solar system bodies that have solid surfaces (Melosh, 1989). The planet Earth is a typical body in our solar system in many aspects, e.g., Earth's cratering history is the same as that of the other inner solar system bodies (Strom et al., 2005, 2015). However, as of April 2019, just over 190 impact craters have been confirmed on Earth (http://www.passc.net/ EarthlmpactDatabase/), of which $\sim 170$ are larger than $1 \mathrm{~km}$ in diameter. Earth's Moon has obviously been bombarded by the same impactor population as Earth, but the impact flux on the Moon is much lower, due to the Moon's smaller gravitational well (Minton and Malhotra, 2010). However, more than one million craters larger than $1 \mathrm{~km}$ have been found on the Moon (Robbins, 2019). This startling difference raises the question: Where have Earth's im-

Correspondence to: Z. Y. Xiao, zyxiao@cug.edu.cn

Received 15 APR 2019; Accepted 24 MAY 2019.

Accepted article online 14 JUN 2019.

(C) 2019 by Earth and Planetary Physics. pact craters gone? The answer is related to one of the unique characteristics of Earth among all terrestrial bodies, i.e., the existence of global-scale plate tectonics on our planet (Le Pichon, 1968), which has resulted in a rapid surface modification process that has completely removed evidence of $>99 \%$ of previouslyformed impact craters (Johnson and Bowling, 2014), since the average age of the Earth's ocean lithosphere is $<300 \mathrm{Ma}$ (Müller et al., 2008). A further question, however, is raised by the stratigraphic distribution of confirmed Earth impact craters (Xiao ZY et al., 2018), which clearly shows that there are some near-blank areas on Earth's continents, regions in which the number of confirmed Earth impact craters is exceptionally small, such as the territory of China. So far, only the Xiuyan crater in the Liaoning Province has been confirmed as an impact crater in China (Chen M, 2008; Chen M et al., 2010).

After more than 50 years of intensive study of confirmed Earth impact craters, it is well-accepted that impact cratering is an unignorably important geologic process on Earth. Referring to the spatial distribution and erosion extent of confirmed Earth impact craters, Hergarten and Kenkmann (2015) estimated the theoretical number of various-sized undiscovered impact craters on Earth's 
surface. Employing their algorithm, we estimated that there should be more than 13 craters larger than $1 \mathrm{~km}$ in diameter still preserved on the surface of China (Xu XM et al., 2017). However, as mentioned above, so far only one crater has been identified in the geological record in China. Therefore, for the last five years we have been looking for potential impact craters in China. The strategy of our search program has been introduced in Xu XM et al. (2017), Xiao ZY et al. (2018) and Pu J et al. (2018).

This paper reports on our recent investigaton of the Lidang crater in the center of Guangxi Province. This excursion is another successful false-confirmation of our working code: that most circular features with negative topography on Earth's surface are not formed by impact cratering, and that field study and sample analyses are the only method to test the impact hypothesis (French and Koeberl, 2010).

\section{Geological Background}

The Lidang structure is a circular shallow depression approximately 8 kilometers in diameter with maximum relief of $\sim 500 \mathrm{~m}$ (Figure 1b) located in the Mashan county of the Guangxi Province, southern China. The coordinates of Lidang, located in the center of this structure, are $23.9^{\circ} \mathrm{N}, 108.4^{\circ} \mathrm{E}$ (Figure $1 \mathrm{a}$ ). The structure exhibits a negative topography and the interior is dominated by relatively low mountains (Figure 1c), but it does not show raised crater rims (Figure 1c).

The stratigraphy of this area is composed of two part: a MesoNeoproterozoic basement and a Phanerzoic sedimentary cover (Zhou WB, 2005; RGSPGZA, 1971). The Caledonian movement during the Cambrian to Silurian caused intense tectonic activity in this area, which was a marine basin during most of the Late Devonian to the Late Triassic, although the marine environment was interrupted several times, e.g., during the Hercynian and Indosinian movements. Since the Late Triassic, this area has been largely in a continental environment characterized by continuous uplifting and denudation (Yang HY, 2010; Zhou WB, 2005). Around the Lidang crater, several-kilometer-thick marine sediments are exposed that are mainly composed of Devonian to Permian limestone and dolomite (Figure 2). Geological mapping has showed that all these strata exhibit primarilly conformable contacts with each other (RGSPGZA, 1971).

The morphological rim of the Lidang crater corresponds well with the conformable contact between the Upper Permian Maokou Formation and the Lower Permian Qixia Formation (Figure 2). The Maokou Formation occupies the center of the Lidang crater; the surrounding Qixia Formation occurs as a narrow belt. Both the Qixia and Maokou formations consist mainly of limestone, but those of the Maokou formation are interbedded with shales that have a higher bulk content of mud (RGSPGZA, 1971). Rocks younger than the Late Permian in this area occur only in some Mesozoic pull-apart basins, and they are not visible within or around the Lidang crater (Figure 2), suggesting that the horst where the Lidang crater is located (Figure 2) has been more or less continuously uplifted since the end of the Late Permian.

The Lidang circular depression is abnormal in this region, in both morphology and topography. The region exhibits two obvious sets of regional joints, with strikes NNW-SSE and NE-SW, respectively (Figure 1a). The joints are continuous along the strikes, except when encountering regional faults (Figures $1 \mathrm{a}$ and 2), and they transect all the geological units from the Lower Devonian to the Upper Permian, but are not developed in the Triassic or younger strata (Figures $1 \mathrm{a}$ and 2), indicating that the joints were formed before the Triassic and remained active at least postdating the Early Permian Qixia Formation. On the other hand, the overall topography of this region (Figure 1a) is dominated by karst landform (Li QS et al., 2008). The spatial distribution of the toprounded mountains exhibits a grid pattern, suggesting that the evolution of the karst landforms topography has been controlled by the regional joints and faults (Figure 2). However, optical remote sensing images show that the joint system abruptly stops right on the rim of the Lidang structure (Figures $1 \mathrm{a}$ and $1 \mathrm{~b}$ ), indicating that this structure has disturbed the regional topography and is younger than or was formed together with the joint system.

The uniqueness of the Lidang circular structure in this region, its circular plane morphology, and its negative topography make it an impact crater candidate in our database. Furthermore, the crater interior is occupied by limestone from the Upper Permian Maokou Formation, surrounded by limestone from the older Qiaxia Formation, a stratigraphic relationship that also could be consistent with an impact origin that happened between the Late and Early Permian, as the Qixia Formation might be seen as impact ejecta and the Maokou formation as crater infill (Figure 3; French, 1998). The above observations and the regional geological data triggered us to perform a field excursion to this crater in June 2018 to assess the impact hypothesis.

It should be noted that not all the topographic characteristics of the Lidang crater are fully consistent with the impact hypothesis. For example, confirmed Earth impact craters larger than $\sim 2 \mathrm{~km}$ in diameter that are formed in sedimentary rocks are complex craters, but there is no obvious sign of a central peak feature on the crater floor of Lidang (Section 3.1). On the other hand, this area is a dominated by karst landforms (Li QS et al., 2008), and previous geological mapping has confirmed that carbonate rocks dominate the whole area. Therefore, it is more intuitive to speculate that the Lidang structure was formed by erosion (Section 4).

\section{Research Strategy and Field Investigation}

\subsection{Research Strategy}

Our working strategy to assess the possibility of an impact origin for the Lidang structure is a falsification process, fulfilled by two parts: (1) assuming the impact origin is true, we first enumerate all the possible impact ages based on the stratigraphic crosscutting relationships in this region (Section 3.1); (2) during the field trip, we seek evidence against each of the hypothesized impact ages, to refute the impact hypothesis (Section 3.2).

Distinctive shock evidence in carbonate rocks has not been firmly established (French and Koeberl 2010), and many aspects of the shock behavior of carbonate minerals are still highly debated, e.g., whether decomposition or melting occurs in calcite upon shock loading and release (e.g., Osinski et al., 2008). Therefore, during 


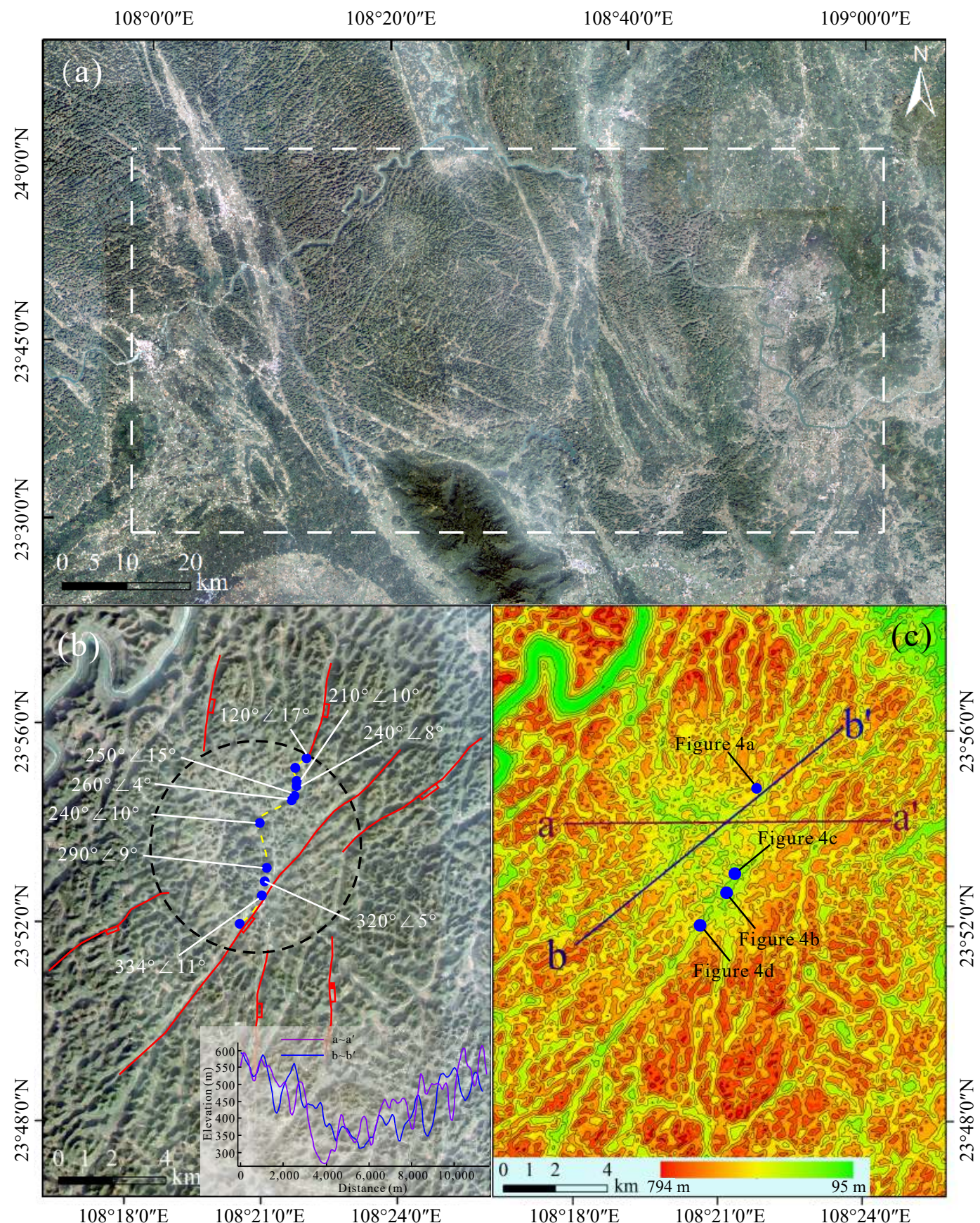

Figure 1. The location, morphology, and topography of the Lidang crater. (a) Google Earth image ( 17.5 m/pixel), showing that the Lidang crater is an abnormal shallow depression that has transected the regional joint system. This area is covered by dense vegetation. The inset box denotes the boundary of the geological map shown in Figure 2. (b) Detailed view of the Lidang crater, showing the crosscutting relationship with the regional joint systems (marked in red lines). The rim of the Lidang crater is marked as the black dashed circle. The yellow dashed line denotes the field investigation route, and the blue dots are locations that have been inspected during the field survey. The inset figure shows two elevation profiles across the crater, which are derived from the digital elevation model shown in (c). The locations of the topography profiles are marked in panel (c). The base image is from Google Earth ( $4.6 \mathrm{~m} /$ pixel). (c) Topography map, showing that the Lidang crater is a shallow depression. Numerous small and isolated mountains occupy the crater floor. Blue dots denote locations of photos taken at Figure 4. Black lines are contours that are spaced at intervals of $100 \mathrm{~m}$. The digital elevation model is from the Advanced Spaceborne Thermal Emission and Reflection Radiometer (ASTER; https://earthexplorer.usgs.gov/; horizontal resolution 30 m/pixel; vertical accuracy 10-25 m).

the field trip, structural disturbances in outcrops both within and outside of the Lidang crater were our key target for observation and sampling, and a particular focus was placed on hunting for possible shatter cone features, which should be abundant in impact craters of this size that are formed in limestone (French and Koeberl, 2010). 


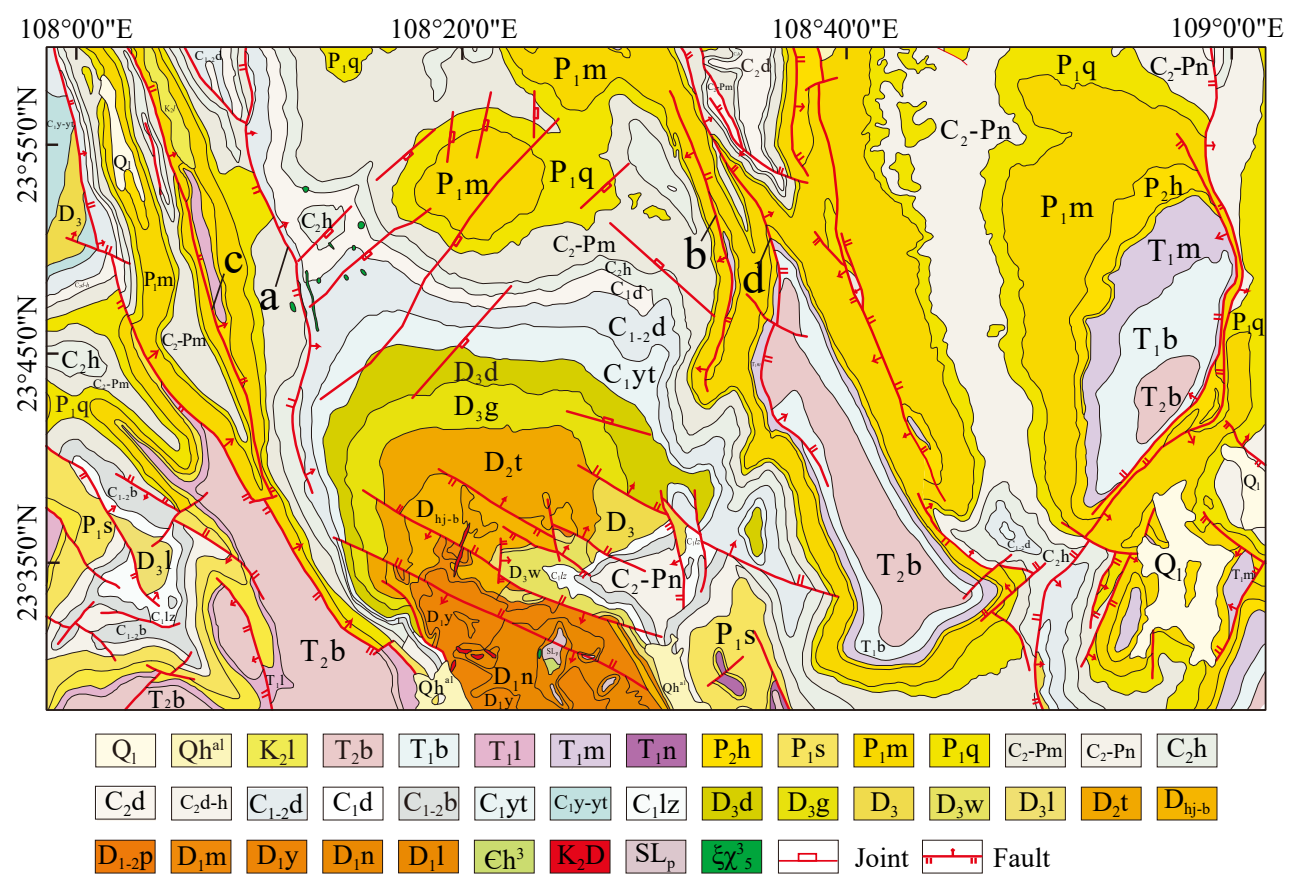

Figure 2. Geological map of Lidang circular structure and the surrounding area (revised from RGSPGZA, 1971). The Lidang crater is located on top of a tilted block that is bounded by two thrust faults (faults a and b), and the whole block is part of a horst that has a higher relief than the surrounding pull-apart basins (faults $\mathrm{c}$ and $\mathrm{d}$ ). The interior of the Lidang crater is occupied by Upper Permian limestone, and the immediate surrounding is Lower Permian limestone. The figure legend includes strata, igneous rocks, major faults, and joints in this area.

Crosscutting relationship shows that the Lidang structure must have obtained its circular morphology after the deposition of the Qixia formation in the Early Permian. Otherwise, the regional joints should wholly transect the interior of the Lidang crater, considering that both the interior and exterior of this crater are composed primarily of limestone. The topographic rim of the Lidang crater is dominated by Qixia Formation limestone, suggesting that if it was an impact crater, the impact event should postdate the Qixia Formation. Based on the occurrence of the post-Qixia Formation strata around this crater (Figure 2), the Lidang structure can have been formed only after the Early Permian, i.e., between the deposition of the Qixia and Maokou Formations (Scenario 1 in Figure 3), or after the Late Permian (Scenario 2 in Figure 3). Both models are potentially capable of producing a strata configuration similar to what is observed inside and outside of the crater.

According to the Scenario 1, the rim of the Lidang crater should be the degraded rim/wall of the hypothesized impact crater; thus, strongly visible structural disturbance would be expected at the contact between the Qixia and Maokou Formations. According to the Scenario 2, the Maokou Formation within the crater should be remnants of impactites, where strong structural disturbances might be encountered. Therefore, during the field investigation, the crater center and the contact between the Maokou and Qixia Formations were key areas to assess for confirmation of the impact hypothesis.

\subsection{Field Investigation}

Field investigation confirm that the Qixia Formation and the Maokou Formation exhibit conformable contact (Figure 1b), and that the limestone has uniform attitudes without structural disturbances. Therefore, the impact possibilities outlined in Figure 3 can be discarded. We systematically investigated outcrops from the northern crater rim to the southern crater rim. Both the crater rim and crater interior are composed of parallel layers of limestone that have various thicknesses, from about 2 centimeters to over 1 meter (Figure 4). The attitudes of the limestone are uniform from the crater rim to the interior (Figure 2b). Except for pressolutional fractures and small-scale faults (Figures $4 b$ and $4 c$ ), no other structural disturbances were observed over a scale larger than roughly $20 \mathrm{~m}$ (Figure $4 \mathrm{a}$ ). This observation excludes airburst as a possible origin of the Lidang circular structure, because airburst normally does not form excavated craters, and we should also see abundant structural disturbances within the crater (Shuvalov and Trubetskaya, 2007). Furthermore, our field investigations confirm the previous regional geological mapping results (RGSPGZA, 1970), finding that blackish flint stripes are occasionally visible within the limestone in the crater interior (Figure $4 \mathrm{~d}$ ), and the limestone within the crater is interbedded with a higher abundance of shale layers (Figure 4c). No pseudo-impactites were encountered during the field trip, so there was no need to take samples for further analyses.

\section{Discussion and Conclusion}

While the impact origin of the Lidang circular structure can be disapproved, our remote sensing and field investigations suggest that this circular structure is probably a polje, which is a shallow limestone basin formed by karstification. So far, the best digital elevation model (i.e., DEM) for this area in the public domain is the 


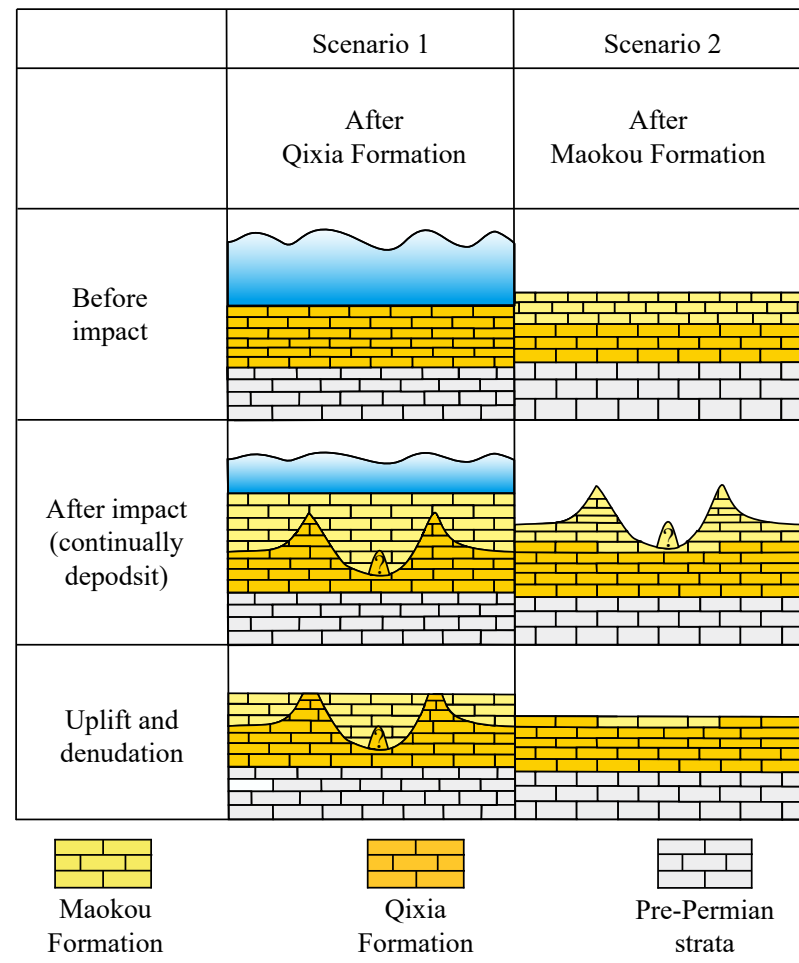

Figure 3. Stratigraphic models of the Lidang structure, assuming it was formed by impact cratering. The models have considered marine deposition of Permian and older rocks, and the post-Permian erosion based on the regional geological history (RGSPGZA, 1970). The establishment of these models is based on the present spatial configuration of the strata, i.e., the fact that the crater rim is composed of the Qixia Formation and the crater interior is occupied by the Maokou Formation. The regional geological history and the spatial distribution of different-aged strata suggest that if the impact scenario were true, this event can have occurred only after deposition of the Qixia Formation in the Early Permain (Section 3.1). Note that structural disturbances (e.g., impact breccia) are not marked in these schematic diagrams. Scenario 1 shows the theoretical distribution of different-aged strata if the impact event occurred after the deposition of the Qixia Formation and before that of the Maokou Formation.

Scenario 2 shows the theoretical distribution of different-aged strata if the impact occurred after the deposition of the Qixia Formation and before that of the Maokou Formation.

AW3D30 model obtained by the Advanced Land Observing Satellite (https://www.eorc.jaxa.jp/ALOS/en/aw3d30/data/index.htm). This DEM has a lateral resolution of $30 \mathrm{~m} /$ pixel and vertical precision of $5 \mathrm{~m}$. Using this DEM, we have examined the extension of the regional joint system, and the results show that although joints are not visible in the crater interior as seen in optical images (e.g., Figure 1a), they are well traceable in the AW3D30 DEM (Figure 5). The top-rounded mountains in the crater interior are also shaped by dissolution as are similar landforms in this region (Figure 1a). The spatial distribution of these mountains shows that they are aligned along linear structures that are continuously connected with the regional joint system, and with identical orientations (Figure 5). Therefore, the negative topography is consistent with a higher degree of erosion of the Maokou Formation, so that

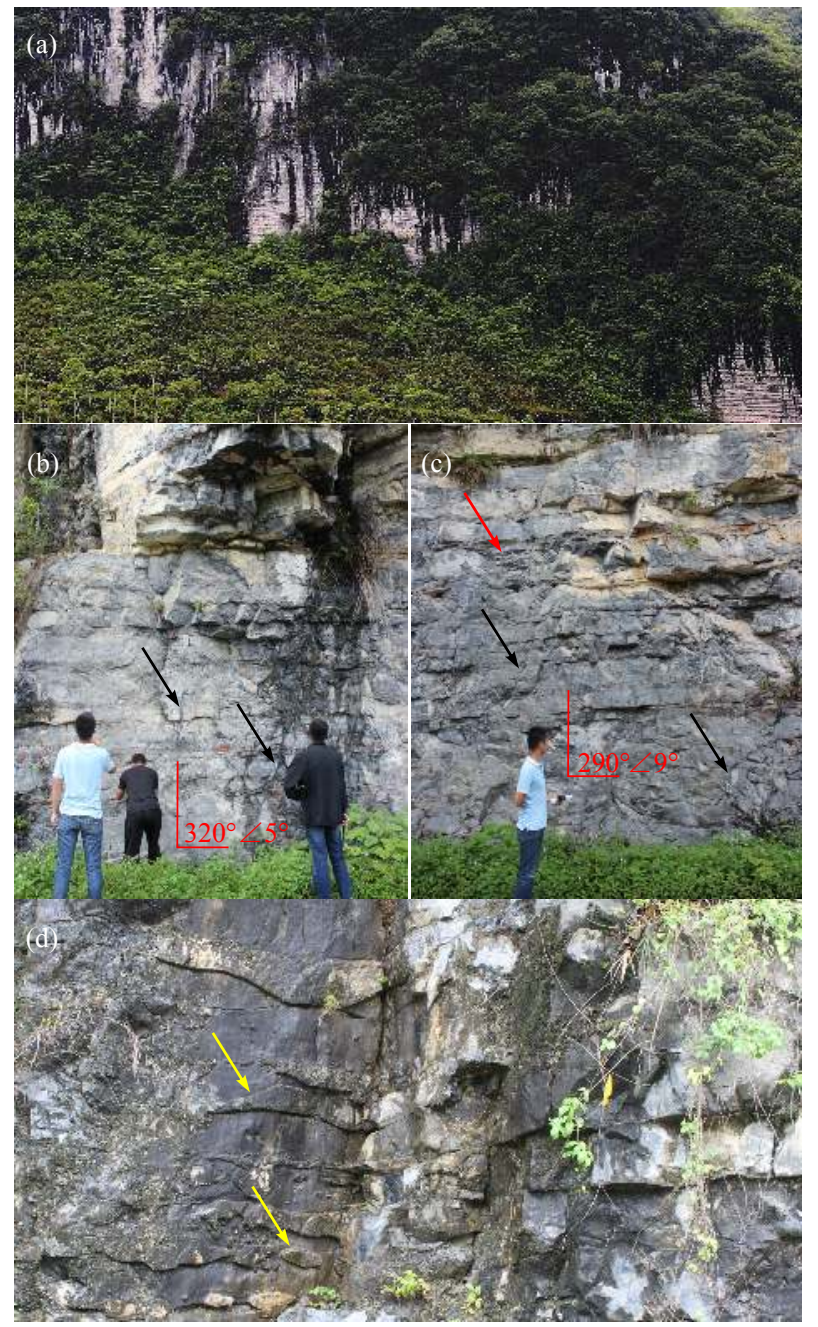

Figure 4. Outcrops within the Lidang circular structure. (a) Parallel layers of limestone near the northern rim of the crater. No structural disturbances larger than $\sim 20 \mathrm{~m}$ were observed. Trees in the lower left corner are about $7 \mathrm{~m}$ high. The camera azimuth about $120^{\circ}$. (b) and (c) are limestones within the southern center of the crater. Single layers of limestone are about 0.1-0.3 m thick. Besides small scale pressolutional fractures (black arrows), there is no obvious regional disturbance. The red arrow in Figure $4 \mathrm{c}$ points to layers of shales that are interbedded with the limestone. The camera azimuths of panel $b$ and $\mathrm{c}$ are $230^{\circ}$ and $200^{\circ}$, respectively. (d) Flint strips (yellow arrows; 3 $\mathrm{cm}$ thick) interbedded with limestones near the southern rim of the crater. The stronger resistance against weathering of flints formed the positive topography. The locations of the photos are denoted in Figure 1c.

regional joints that had once developed within the crater are not traceable in optical images (Figure 1), but the linear topography is still visible (Figure 5). This interpretation is consistent with the much higher content of shale within the limestone in the crater interior (RGSPGZA, 1971; Figure 4).

It is notable that we have also used DEM with similar spatial resolution but obtained at different times to estimate the amount of short-term erosion that has occurred in this region. Similar calculation has been used to monitor the movement of glacial and sim- 


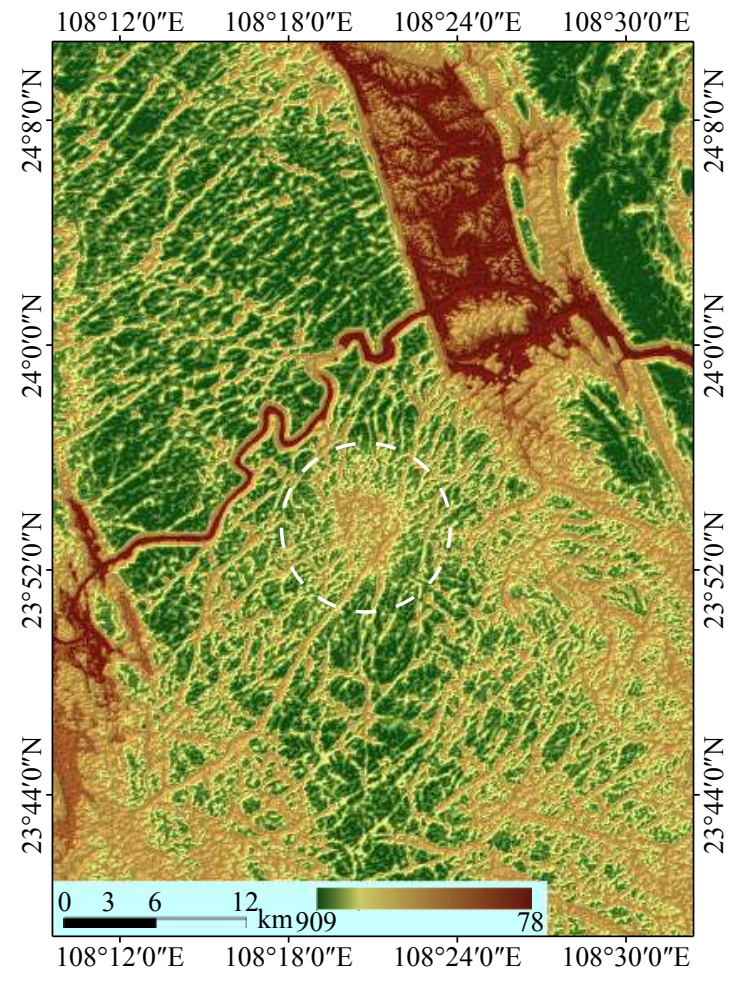

Figure 5. Appearance of joints in the Lidang region as shown by the ALOS AW3D30 DEM. The white dashed circle marks the rim of the Lidang circular structure. Joints continuously extend from the crater exterior to the interior. ilar active surface processes (Pandey and Venkataraman, 2013). DEMs obtained by the Shuttle Radar Topography Mission (i.e., SRTM; https://earthexplorer.usgs.gov/), ASTER, and ALOS have similar lateral resolution, but the original radar and optical camera data that were used to construct the DEMs were obtained at different times. However, this calculation is hampered by minor strips of mismatched data in the DEMs (Figure 6). Therefore, future comparison would integrate local meteorological data and petrology data to quantitatively estimate the erosion rate of this region.

In conclusion, the possible impact origin for the Lidang structure in the Guangxi province is studied here via both remote sensing and field investigation. No structural disturbances were observed in the key strata within and outside of the basin, leading us to conclude that this structure was not formed by impact cratering. The circular shape of this structure may reflect the outline of the original depositional basin when the Maokou Formation was deposited. The higher degree of erosion of the crater interior has formed the uniform polje in this region. The results further suggest that most circular structures on Earth are not astroblemes.

\section{Acknowledgments}

This study is supported by National Natural Science Foundation of China (Nos. 41773063 and 41830214 ), the Science and Technology Development Fund (FDCT) of Macau (0042/2018/A2), and the Fundamental Research Funds for the Central Universities, China University of Geosciences (Wuhan) (Nos. CUG180601).
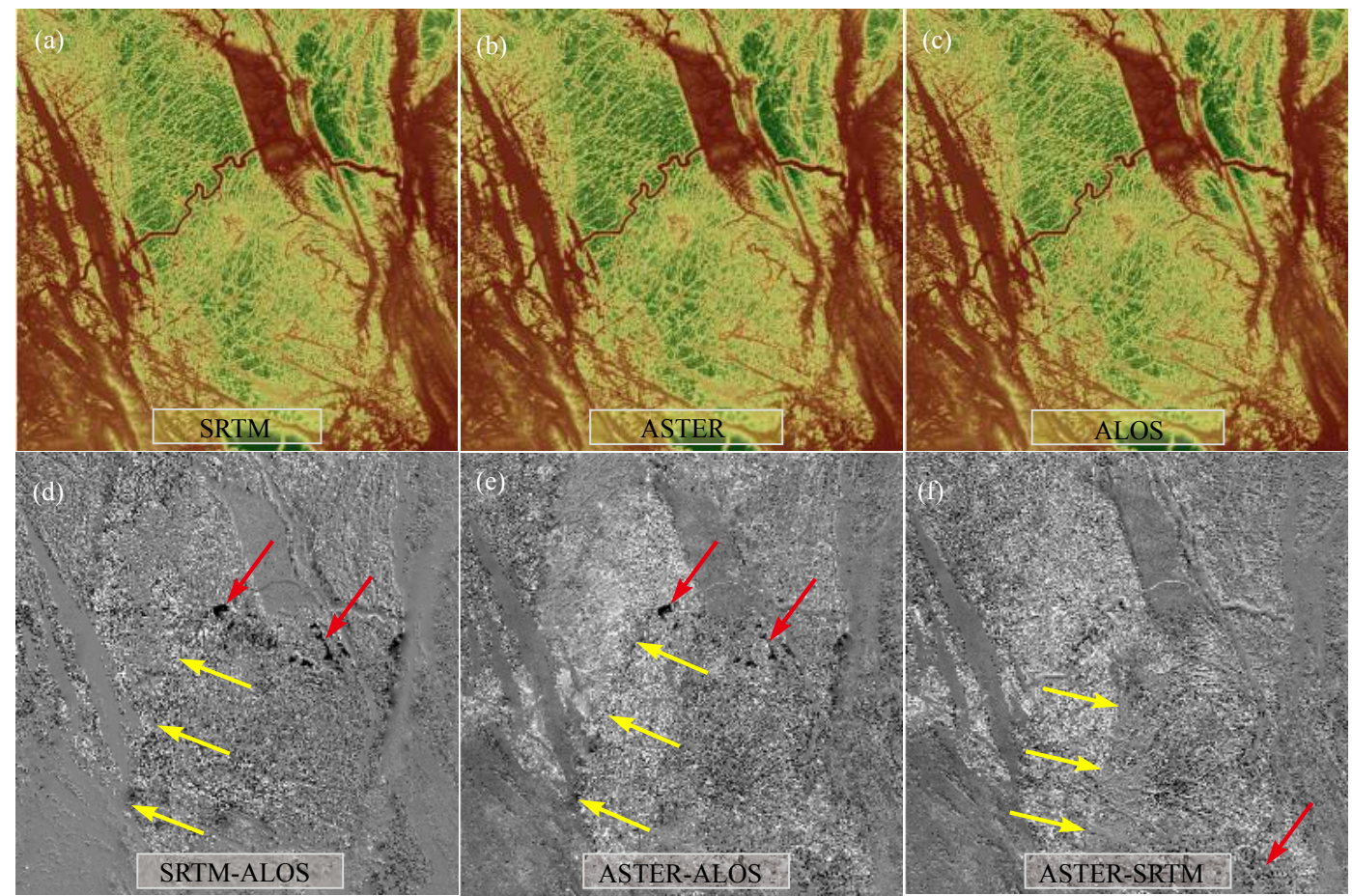

Figure 6. Digital elevation models obtained by the (SRTM; panel a), (ASTER; panel b), and (ALOS; panel c) missions. The spatial resolutions of the three DEMs are identical with each other. ALOS has the highest average quality among the three. The three DEMs are used to estimate the relative degree of short-term erosion in this area. Panels $(d),(e)$ and (f) show the subtract results using an early and later DEM. Strips of invalid data (e.g., yellow arrows) and bad points (e.g., red arrows) exist in the final results. This is due to the imperfect quality of the original DEM caused by meter scale mismatches, which are not obvious in the original DEM, but they are highlighted in the subtracted results. 


\section{References}

Chen, M. (2008). Impact-derived features of the Xiuyan meteorite crater. Chin. Sci. Bull., 53(3), 392-395. https://doi.org/10.1007/s11434-008-0004-3

Chen, M., Xiao, W. S., Xie, X. D., Tan, D. Y., and Cao, Y. B. (2010). Xiuyan crater, China: impact origin confirmed. Chin. Sci. Bull., 55(17), 1777-1781. https://doi.org/10.1007/s11434-010-3010-1

French, B. M. (1998). Traces of Catastrophe: A Handbook of Shock-Metamorphic Effects in Terrestrial Meteorite Impact Structures. Houston: Lunar and Planetary Institute.

French, B. M., and Koeberl, C. (2010). The convincing identification of terrestrial meteorite impact structures: what works, what doesn't, and why. Earth-Sci. Rev., 98(1-2), 123-170. https://doi.org/10.1016/j.earscirev.2009.10.009

Hergarten, S., and Kenkmann, T. (2015). The number of impact craters on Earth: Any room for further discoveries?. Earth Planet. Sci. Lett., 425, 187-192. https://doi.org/10.1016/j.epsl.2015.06.009

Johnson, B. C., and Bowling, T. J. (2014). Where have all the craters gone? Earth's bombardment history and the expected terrestrial cratering record. Geology, 42(7), 587-590. https://doi.org/10.1130/G35754.1

Le Pichon, X. (1968). Sea-floor spreading and continental drift. J. Geophys. Res., 73(12), 3661-3697. https://doi.org/10.1029/JB073i012p03661

Li, Q. S., Li, Z. L., Pei, J. G., Qin, X. Q., Yi, L. X., and Liang, M. Z. (2008) Characteristics of waterlogging and management planning in karst depressions and valley in the east Mashan. Carsol. Sin. (in Chinese), 27(4), 359-365. https://doi.org/10.3969/j.issn.1001-4810.2008.04.011

Melosh, H. J. (1989). Impact Cratering: A Geologic Process (pp. 215-222). New York: Oxford University Press.

Minton, D. A., and Malhotra, R. (2010). Dynamical erosion of the asteroid belt and implications for large impacts in the inner Solar System. Icarus, 207(2), 744-757. https://doi.org/10.1016/j.icarus.2009.12.008

Müller, R. D., Sdrolias, M., Gaina, C., and Roest, W. R. (2008). Age, spreading rates, and spreading asymmetry of the world's ocean crust. Geochem., Geophys., Geosyst., 9(4), Q04006. https://doi.org/10.1029/2007GC001743

Osinski, G. R., Spray, J. G., and Grieve, R. A. F. (2008). Impact melting in sedimentary target rocks: an assessment. In K. R. Evans, et al. (Eds.), The Sedimentary Record of Meteorite Impacts (Vol. 437, pp. 1-18). Boulder, Colo.: Geological Society of America. https://doi.org/10.1130/2008.2437(01)

Pandey, P., and Venkataraman, G. (2013). Comparison of DEMs derived from TanDEM-X and SRTM-C for Himalayan terrain. In Proceedings of 2013 IEEE International Geoscience and Remote Sensing Symposium (pp. 322-325). Melbourne, VIC, Australia: IEEE.
https://doi.org/10.1109/IGARSS.2013.6721157

Pu, J., Xiao, Z. Y., Xiao, L., and Huang, C. (2018). Non-Impact origin of the Baisha structure in Hainan Province, China. J. Earth Sci.. https://doi.org/10.1007/s12583-018-0887-0

RGSPGZA (Regional Geological Surveying Party of Guangxi Zhuang Autonomous). (1970). Regional Geological Survey Report for the Shanglin Frame (1:200,000) (in Chinese).

RGSPGZA (Regional Geological Surveying Party of Guangxi Zhuang Autonomous). (1971). Geological Map of the Shanglin Frame (1:200,000) (in Chinese).

Robbins, S. J. (2019). A new global database of lunar impact craters >1-2 km: 1. Crater locations and sizes, comparisons with published databases, and global analysis. J. Geophys. Res.: Planets, 124(4), 871-892. https://doi.org/10.1029/2018JE005592

Shuvalov, V. V., and Trubetskaya, I. A. (2007). Aerial bursts in the terrestrial atmosphere. Sol. Syst. Res., 41(3), 220-230. https://doi.org/10.1134/S0038094607030057

Strom, R. G., Malhotra, R., Ito, T., Yoshida, F., and Kring, D. A. (2005). The origin of planetary impactors in the inner solar system. Science, 309(5742), 1847-1850. https://doi.org/10.1126/science.1113544

Strom, R. G., Malhotra, R., Xiao, Z. Y., Ito, T., Yoshida, F., and Ostrach, L. R. (2015). The inner solar system cratering record and the evolution of impactor populations. Res. Astron. Astrophys., 15(3), 407-434. https://doi.org/10.1088/1674-4527/15/3/009

Xiao, Z. Y., Chen, Z. X., Pu, J., Xiao, X., Wang, Y. C., and Huang, J. (2018). Hailar crater-A possible impact structure in Inner Mongolia, China. Geomorphology, 306, 128-140. https://doi.org/10.1016/j.geomorph.2018.01.020

Xu, X. M., Kenkmann, T., Xiao, Z. Y., Sturm, S., Metzger, N., Yang, Y., Weimer, D., Krietsch, H., and Zhu, M. H. (2017). Reconnaissance survey of the Duolun ring structure in Inner Mongolia: not an impact structure. Meteorit. Planet. Sci., 52(9), 1822-1842. https://doi.org/10.1111/maps.12890

Yang, H. Y. (2010). Pattern and evolution of the devonian-middle triassic tectono-palaeogeography in Hunan and Guangxi Provinces [Ph. D. thesis] (in Chinese). Qingdao: China University of Petroleum (East China). https://doi.org/10.7666/d.y1778077

Zhou, W. B. (2005). Structural characteristics of the Xidamingshan uplift in Guangxi and its relationship with the adjacent basins [Ph. D. thesis] (in Chinese). Beijing: China University of Geosciences (Beijing). 